\title{
Effect of Female Sexual Dysfunction on Self- Esteem of Infertile Women in Osun East Senatorial District Southwest Nigeria
}

\author{
Orji Ernest $\mathrm{O}^{1^{*}}$, Ogunjuyigbe Peter $\mathrm{O}^{2}$ \\ ${ }^{1}$ Department of Obstetrics and Gynaecology, Obafemi Awolowo University, Ile-Ife. Obafemi \\ Awolowo University Teaching Hospital Complex, Ile-Ife, Nigeria \\ ${ }^{2}$ Demography and Social Statistics, Obafemi Awolowo University, Ile-Ife, Nigeria
}

\begin{abstract}
This study assessed the effect of sexual Dysfunction on the self-esteem between infertile and fertile married women in Ife East Senatorial district Southwest Nigeria. This was a comparative crosssectional study using both quantitative and qualitative methods of data collection. It was conducted at infertility and family planning clinics of Obafemi Awolowo University Teaching Hospitals Complex IleIfe, Nigeria. Using stratified random sampling, 222 infertile women at infertility clinic and 222 family planning clients who met inclusion criteria were recruited from 2020 to 2021. Quantitative data was assessed using the Rosenberg self-esteem questionnaire, while an in-depth interview guide was employed to collect qualitative data. Data were managed using SPSS version 22. $P$-value was set at $P$ $<0.05$. Fifty $(22.5 \%)$ infertile women had low self-esteem compared with five $(2.3 \%)$ of fertile women. which was statistically significant $(P<0.001)$. Among fertile women, female sexual Dysfunction did not affect self-esteem $(P=0.346)$, but among infertile women, female sexual Dysfunction significantly affected self-esteem $(P=0.016)$. There is a positive relationship between female sexual function index scores and self-esteem scores among fertile and infertile women ( $r=0.294$ and 0.354 respectively) $p<0.001$ Sexual dysfunctions among infertile women adversely affected their self-esteem.
\end{abstract}

Keywords: Female Sexual Dysfunction, Infertile women, Nigeria.

\section{Introduction}

Female sexual Dysfunction has been described as syndromes that comprise the various ways in which people may have difficulty experiencing personally satisfying non-coercive sexual activities" $[1,2]$. Female sexual Dysfunction was redefined and now includes Female Sexual Interest/Arousal Disorder and Female Orgasmic Disorder, and Genitopelvic Pain/Penetration Disorder. To be considered dysfunctional, these symptoms must cause distress and must occur at least $75 \%$ of the time over of 6-month period [3]. Infertility is one condition with adverse psychological, economic, and socio-cultural implications resulting in marital distress, particularly in the African context, with a strong emphasis on childbearing [4-9].

Therefore, sexual Dysfunction and infertility are two conditions that cause significant distress to the couple. The magnitude of sexual Dysfunction among infertile Nigerian women is largely understudied. More scarce are studies on the effect of sexual Dysfunction on the selfesteem of infertile Nigerian women using validated instruments or tools. Self-esteem has been described as one of the important aspects of personality and determinants of human behavior and wellbeing. It indicates the degree to which a person perceives him/herself as able, valuable, and important to society [9-13]. On the other hand, general self-esteem is used to describe a person's overall sense of self-worth or personal value. 
Though both couples face the challenge, of infertility the women feel guilt, stress, and responsibility more than the men do. Due to this fact, even if the crux of infertility is not from the woman, the blame is often placed on women [1416]. While some studies had been conducted on sexual Dysfunction in the Nigerian female population [5,14-16], there is no study specifically assessing the effect of female sexual Dysfunction on the self-esteem of infertile Nigerian women using validated tools. Such study is imperative as it will guide practitioners in evaluating and treating affected women to deliver holistic care that will improve the overall quality of life [11, 17-19]. The objective of this comparative study was to assess the effect of sexual Dysfunction on the self-esteem between infertile and fertile married women using validated tools in Ife East Senatorial district Southwest Nigeria.

\section{Methods}

This was a comparative cross-sectional study that employed a mixed-method approach using both quantitative and qualitative methods of data collection. The objective of this comparative study was to assess the effect of sexual Dysfunction on the self-esteem between infertile and fertile married women. This study was conducted at infertility and family planning clinics of the Department of Obstetrics and Gynaecology of the Obafemi Awolowo University Teaching Hospitals Complex Ile-Ife Nigeria. Using stratified random sampling, 222 infertile women at an infertility clinic and 222 family planning clients (fertile women) who met inclusion criteria were recruited from 2020 to 2021. Quantitative data on self-esteem was assessed using the Rosenberg self-esteem questionnaire as used by Çavdar and Coşkun, 2018 [11], which contained 10 questions with agree/disagree choices. The 10-item scale measured global self-worth by measuring both positive and negative feelings about the self. The scale was believed to be uni-dimensional. All items were answered using a 4-point Likert scale format ranging from strongly agree to disagree strongly. Items 2, 5, 6, 8, 9 are reverse scored. Give "Strongly Disagree" 1 point, "Disagree" 2 points, "Agree" 3 points, and "Strongly Agree" 4 points. The maximum sum of scores for all ten items was 40, and the minimum was 10 . Scores were placed on a continuous scale. Higher scores indicate higher self-esteem. The scale ranges from 0-30. Scores between 15 and 25 are within the normal range; scores below 15 suggest low self-esteem. For qualitative data collection, an in-depth interview guide was employed to elicit insight to patients' feelings and experiences of sexual Dysfunction, perceived reasons for sexual Dysfunction, and self-esteem. The responses were triangulated with the results of the quantitative data. Six patients with sexual Dysfunction were recruited for this in-depth interview.

Data were analysed by SPSS version 22 using ANOVA and Pearson and Spearman correlation coefficients. P-value $<0.05$ was considered as statistically significant. This study was approved by the Ethics and Research Committee (ERC) of the Obafemi Awolowo University Teaching Hospitals Complex Ile-Ife, Nigeria (Protocol No: ERC/2019/12/14) and by Health Research Ethics Committee, Institute of Public Health, Obafemi Awolowo University, Ile-Ife, Nigeria (Protocol No: IHUOAU/12/1389). Informed consent was obtained from all participants before inclusion in the study.

\section{Results}

Fifty $(22.5 \%)$ infertile women had low selfesteem compared with five $(2.3 \%)$ of fertile women. which was statistically significant at $\mathrm{P}<0.001$. (Table 1). Table 2 showed that among fertile women, female sexual Dysfunction did not affect self-esteem $(\mathrm{P}=0.346)$, but among infertile women, female sexual Dysfunction significantly affected self-esteem $(\mathrm{P}=0.016)$. Table 3 showed that there is a positive relationship between female sexual function index scores and self-esteem scores among fertile and infertile women. The relationship, 
however, is weak among the fertile and infertile groups $(r=0.294$ and 0.354 respectively) $\mathrm{p}<0.001)$. There is also a positive relationship between female sexual function index scores in all the domains and self-esteem scores among fertile and infertile women. The scale ranges from 0-30. Scores between 15 and 25 are within the normal range; scores below 15 suggest low self-esteem.

Table 1. Comparing Self-Esteem Between Fertile and Infertile Women

\begin{tabular}{|l|l|l|l|l|l|l|}
\hline \multirow{3}{*}{ Type of respondent } & \multicolumn{9}{|l|}{ Self Esteem category } & \multicolumn{2}{l|}{ Statistics } \\
\cline { 2 - 7 } & Low & \multicolumn{2}{l|}{ Normal } & \multicolumn{2}{l|}{} \\
\cline { 2 - 6 } & $\mathbf{N}$ & $\mathbf{\%}$ & $\mathbf{N}$ & $\mathbf{\%}$ & $\chi^{2}$ & $\mathbf{P}$ \\
\hline Fertile & 5 & 2.3 & 217 & 97.7 & 42.024 & $<0.001$ \\
\hline Infertile & 50 & 22.5 & 172 & 77.5 & & \\
\hline
\end{tabular}

Table 2. Relationship between Female Sexual Dysfunction and Self-esteem between Fertile and Infertile Women

\begin{tabular}{|c|c|c|c|c|c|c|}
\hline \multirow[t]{4}{*}{ FSD } & \multicolumn{3}{|c|}{ Fertile women } & \multicolumn{3}{|l|}{ Infertile } \\
\hline & \multicolumn{2}{|c|}{ Self-esteem } & \multirow[t]{3}{*}{ Statistics } & \multicolumn{2}{|l|}{ Self-esteem } & \multirow[t]{3}{*}{ Statistics } \\
\hline & Low & Normal & & Low & Normal & \\
\hline & N (\%) & $\mathbf{N}(\%)$ & & N (\%) & $\mathbf{N}(\%)$ & \\
\hline Yes & $3(60.0 \%)$ & $85(39.2 \%)$ & $\chi^{2}=0.886$ & $36(72.0 \%)$ & $91(52.1 \%)$ & $\chi^{2}=5.769$ \\
\hline No & $2(40.0 \%)$ & $132(60.8 \%)$ & $\mathrm{p}=0.346$ & $14(28.0 \%)$ & $81(47.1 \%)$ & $\mathrm{p}=0.016$ \\
\hline
\end{tabular}

Table 3. Using Correlation to Test Relationship between Self-esteem and Female Sexual Dysfunction

\begin{tabular}{|l|l|l|l|l|}
\hline \multirow{2}{*}{ Female Sexual function index score } & \multicolumn{2}{|l|}{ Fertile women } & \multicolumn{2}{l|}{ Infertile women } \\
\cline { 2 - 5 } & $\mathbf{R}$ & $\mathbf{P}$ & $\mathbf{R}$ & $\mathbf{P}$ \\
\cline { 2 - 5 } & 0.294 & $<0.001$ & 0.354 & $<0.001$ \\
\hline Desire & 0.294 & $<0.001$ & 0.376 & $<0.001$ \\
\hline Arousal & 0.185 & 0.006 & 0.390 & $<0.001$ \\
\hline Lubrication & 0.141 & 0.036 & 0.248 & $<0.001$ \\
\hline Orgasm & 0.305 & $<0.001$ & 0.223 & 0.001 \\
\hline Satisfaction & 0.102 & $<0.001$ & 0.374 & $<0.001$ \\
\hline Pain & 0.213 & 0.001 & 0.146 & $<0.001$ \\
\hline
\end{tabular}

\section{Results from In-depth Interview for Infertile Patients}

This in-depth interview offered the opportunity to capture rich, descriptive data about how infertile women with sexual Dysfunction think, believe, and behave about the problems of sexual Dysfunction. Six women with low sexual dysfunctions scores were interviewed. Here is the excepts from the indepth interviews.
The First patient - A 45-year-Old Civil Servants has this to Say:

"You know marriage in Nigeria is useless without having children. My experience is not palatable. I moved from doctor to doctor. I did a lot of tests, and after some years, I got disinterested about sexual activity. The desire for sexual intercourse reduced, arousal became difficult, lubrication almost impossible without a gel. After ten years of marriage, my husband 
divorced me, and I remarried. I am saving money for in-vitro fertilization with my new partner".

\section{How Would Describe your Self-esteem?}

I am an unhappy woman. Life has no meaning to me. I feel like a failure. I have lost my selfconfidence. It seems everybody knows better than me. My sexual life is very poor and not satisfying.

\section{The Second Infertile Women -a 40-year-old Teacher has This to Say:}

"I have been married for 15 years, and marital life is no longer as enjoyable as during the first 2 years of marriage. After several years of marriage without pregnancy, we started visiting different hospitals, prayer houses, churches, and herbalists. We used different medications both orally, vaginally, and some injections. We also conducted different blood tests - hormonal assay, HSG, even laparoscopy. With nothing positive forth-coming, I lost interest in sexual intercourse. Different doctors, nurses, and herbalist has touched my vagina, and I don't fancy sex again. My desire and arousal has gone. I feel pain while having sex due to a lack of vaginal lubrication, which was not there before. Sometimes my husband gets angry with me. He had impregnated another woman outside the matrimonial home, and he is threatening to divorce me if I do not produce children for him. I now see sex as a duty to be performed instead of a pleasure to be enjoyed. I needed pregnancy by all means. My doctor advised IVF, but where will I get the money for IVF? It is very costly."

\section{How Would Describe your Self-esteem?}

Useless. What is marriage without a child? I have lost hope. May God intervene.

\section{The Third Infertile Woman - a 42-year Business Tycoon a University Graduate has this to Say"}

My sexual life has nose-dived after 5 years of marriage without having children. I married late and was looking for many children in quick succession, but nothing has happened. I have attempted in-vitro fertilization and embryo transfer (IVF-ET) twice with no success, but I am saving money for the third attempt. Sex is useless without a baby. It is normal to lose interest in either sexual arousal, desire, lubrication, or orgasm. Even pain during intercourse is now a problem. This is all because of no child in marriage. If a woman has children, she will continue to enjoy the sexual activity, but once there is no pregnancy, sexual complaints are bound to occur. Society is not kind to married women without children. The discrimination is too much".

\section{How would you Describe your Self - esteem?}

I have poor self-esteem. I have no voice in the family and community. No respect from people.

The Fourth Infertile Woman a 35-year-old Nurse Practitioner has this to Say:

"You know yourself that our society cherish children. It is sad to be a nurse and be assisting others with their deliveries without having yours. People will call you all sorts of names. Some will even say you have aborted all the babies in your womb and, as a result, can no longer have yours. All these affects the romantic relationship in the home. Sexual intercourse in marriage, which I so much cherished and preserved my virginity, has become a burden. Sometimes my husband is no longer interested in sex, and my sexual desire and arousal had significantly reduced. I no longer have an orgasm because my mind is always on when my pregnancy will come. It is not a good experience to have".

\section{How Would Describe your Self-esteem?}

I have lost my respect and self-esteem. Even small girls and little women insult and abuse me! Nobody appreciate and understands me!

The fifth Infertile Patients - a 38-year-old Civil Servant, had this Experience to Share:

"I got pregnant following an episode of rape. I was coerced into marrying the man by my 
family. I really did not love the man, and our romantic relationship is poor. He beats me sometimes. I finally divorced him. I later went to visit my children, and he raped me again. I remarried to another man, but the trauma of the repeated rape doesn't allow me to enjoy sexual intercourse. I had become too frigid; I does not have adequate lubrication, and most times I have painful intercourse. I tried using gel, but it is not all that satisfactory." I want to get pregnant for my new husband of 2 years, but nothing is fourth coming. Infertility is frustrating!

\section{How Would Describe your Self-esteem?}

My self-esteem is poor. I felt used and dumped by men. I have lost confidence in myself, in men, and in life generally.

\section{Sixth Infertile Patients -a 35-year-old Banker had this to Say:}

"My sexual life had been adversely affected by this infertility. I enjoyed sexual activities with different men before Marriage and in the early part of my marriage. But after two years into marriage with no children, my interest and desire about sexual activities had reduced significantly. I had aborted unwanted pregnancies thrice before marriage, and I was told that I had blocked tubes arising from the complications of the last unsafe abortion I had before marriage. I now regret having had abortions in the past. I think I am unfortunate as some of my friends who had more abortions than me had married and have delivered many children after the marriage. The Devil is hunting me, and my conscience is condemning me. I believe all these experiencing is making me to dislike sexual intercourse now that I needed it most."

\section{How Would Describe your Self-esteem?}

I will not say that I am happy about life. Sex and life has no meaning again to me. I feel like a failure in all things! I need a child I can call my own.

\section{Discussion}

The objective of this study was to assess the relationship between female sexual Dysfunction and self-esteem of infertile and fertile women. Our findings showed that infertile women have a significantly lower level of self-esteem compared to fertile control (22.5\% versus $2.3 \%$; $\mathrm{P}<0.001)$. This is in keeping with the results of previous studies outside Nigeria [9-13,17-19]. Even among infertile women, those who have sexual Dysfunction were significantly at more risk for low self-esteem compared to infertile women without sexual Dysfunction ( $\chi^{2}$ =5.769; $\mathrm{p}=0.016)$. There is a positive relationship between female sexual function index scores and self-esteem scores among fertile and infertile women. The relationship is weak between the fertile and infertile groups $(r=$ 0.294 and 0.354 respectively among fertile and infertile women, $\mathrm{p}<0.001$ ). Infertile women with low self-esteem also were more significantly likely to have disorders in the domains of desire $(\mathrm{p}<0.001), \quad$ arousal $\quad(\mathrm{p}=0.006), \quad$ lubrication $(\mathrm{p}=0.031)$, orgasm $(\mathrm{P}<0.001)$, satisfaction $(p=0.001)$ but not on pain $(p=0.334)$. The explanation for this is that in Nigeria and most of the African countries, women must have given birth to secure their place in the family and community [-8]. Those who could not have children are deemed, incomplete women. In most instances, the husband of an infertile woman is pressurized by his family to marry a second wife to have children, although he may love his first wife. If the first wife who is an infertile woman, refuses the second marriage, the husband would divorce her.

These situations and circumstances associated with infertility state put the infertile women under severe stress making them feel low selfesteem in general. Due to this, many African women feel that sex is useless if they could not bear children, and this make them less interested in sex, less satisfaction in sex, and have negative 
sexual confidence. This is the views shared by almost all the infertile women at in-depth interview. This is in keeping with the results of some previous studies. In a comparative crosssectional study of 284 Egyptian women, of whom 150 were family planning clients in the control group, and 134 were women with primary infertility in the study group [1], it was demonstrated that women with primary infertility showed lower general self-esteem, sexual satisfaction, sexual relationship, and sexual self-esteem than women with children and the difference was statistically significant. Also, previous studies among Iranian women also found a loss of self-esteem in infertile women [19]. Furthermore, in the study among couples at Heidelberg University's Women's Hospital or at the Fertility Center Berlin [17], the results showed that infertility leads to a loss of spontaneous sexuality and a negative impact on women's sexual self-esteem. It is, however, noteworthy that the Berlin study was conducted using the Self-Esteem and Relationship Questionnaire (SEAR) while. Our study was conducted using Rosenberg Self -esteem tool.

The low self-esteem obtained in our study was clearly supported by the findings at the indepth interviews. Irrespective of their level of education and occupation, the responses were similar, indicating the existence of poor selfesteem among infertile women having sexual Dysfunction compared to those without Dysfunction. The practical implication of this is that gynaecologists and other health care practitioners dealing with infertile women should endeavor to explore the level of selfesteem of their clients and evolve measures and strategies to enhance /improve it. This will not only improve confidence but will also encourage compliance with medication and other modalities of management. The above findings under- scores the importance of addressing sexual Dysfunction so that the self-esteem of infertile women can be improved in Nigeria.

\section{Conclusion}

In conclusion, sexual Dysfunction among infertile women in Ife East Senatorial District Southwest Nigeria adversely affected their selfesteem. Therefore, gynaecologists and other health care workers evaluating infertile women should take cognizance of this and do holistic assessment not only of the fertility status but also the impact of infertility on the self-esteem of the couple.

\section{Acknowledgments}

The authors thank the management of OAU, Ile-Ife, and the Needs Assessment TetFund, grant of the Federal Republic of Nigeria for the Scholarship the Ph.D. research work from which this article was extracted. We thank Ms. Anjuna C, my Student Mentor, for her continuous encouragement, corrections, and instructions during this entire research work. I also appreciate my co-guide, Professor Ogunjuyigbe, for his untiring encouragement. I also appreciate the respondents interviewed in this study and my colleagues for granting me assess to use their patients.

\section{Conflict of Interest}

The authors declare no conflict of interest. 


\section{References}

[1] Reed, G.M., Drescher, J., Krueger, R.B., Atalla, E., Cochran, S.D., First, M.B., Cohen-Kettenis, P.T., Arango-de Montis, I., Parish, S.J., Cottler, S., Briken, P., Saxena, S., (2016). Disorders related to sexuality and gender identity in the ICD-11: revising the ICD10 classification based on current scientific evidence, best clinical practices, and human rights considerations. World Psychiatry. 15(3): 205-221.

[2] American Family Physician (2015). Sexual Dysfunction in women: A Practical approach. American Family Physician; 92(4):281-288.

[3] IsHak, W.W., Tobia, G., (2013) DSM-5 Changes in Diagnostic Criteria of Sexual Dysfunctions. Reprod Sys Sexual Disorders 2: 122. doi:10.4172/2161-038X.1000122.

[4] Orji, E.O., Ogunniyi, S.O., (2001): Sexual behaviour of infertile Nigerian Women. Journal of Obstetrics and Gynaecology, Vol. 21, (No. 3). 303305.

[5] Owonikoko, K.M., Bobo, T.I., Tijani, A.M., Atanda, O.O., (2018). Adversities of being an infertile woman in Ogbomoso- A Semi-Urban Town in Nigeria. Annals of Infertility \& Reproductive Endocrinology 1(1): 1-6.

[6] Upkong, D., Orji, E.O., (2006) Mental Health in the Infertile Women in Nigeria. Turk Psikiyatri Derg, 17(4); 259-265.

[7] Amoo, E.O., Omideyi, A.K., Fadayomi, T.O., Ajayi, M.P., Oni, G.A., Idowu, A.E., (2017). Male reproductive health challenges: appraisal of wives coping strategies. Reproductive Health. 28;14(1):90. doi: 10.1186/s12978-017-0341-2.

[8] Orji, E.O., Kuti, O., Fasubaa, O.B., (2002) Impact of infertility on marital life in Nigeria. Int J Gynaecol Obstet. Oct;79(1):61-2.

[9] Zayed, A.A., El-Hadidy, M.A., (2020). Sexual satisfaction and self-esteem in women with primary infertility. Middle East Fertility Society Journal 25:13: $1-5$ https://doi.org/10.1186/s43043-02000024-5.

[10] Jamali, S., Poornowrooz, N., Mosallanezhad, Z., Alborzi, M., (2018). Sexual Satisfaction and SelfEsteem and Stress in Reproductive-Age Women. Journal of Clinical and Diagnostic Research. 12(10): QC16-QC19.
[11] Çavdar, N.K., Coşkun, A.M., (2018). The effect of infertility upon the quality of life and self-esteem. MOJ Women's Health;7(3):89-94. DOI: 10.15406/mojwh.07.00176.

[12] Mojarrad-kahani, A.H., Ghanavi, S., (2012) The efficacy of effective communication skills training on the self-esteem of girls with physical mobility disability. J Res Rehabil Sci 1:263-271.

[13] Ashraf, D.M., Ali, D., Azadeh, D.M., (2015). Effect of infertility on Sexual Function: A Crosssectional Study, Journal of clinical and diagnostic research JCDR;9(5): Qc01-3.

[14] Fajewonyomi, B. A., Orji, E. O., Adeyemo, A. O., (2007). Sexual Dysfunction among female patients of reproductive age in a hospital setting in Nigeria. Journal of Health, Population, and Nutrition; 25(1), 101.

[15] Nwagha, U. I., Oguanuo, T. C., Ekwuazi, K., Olubobokun, T. O., Nwagha, T.U., Onyebuchi, A. K., Ezeonu, P. O., Nwadike, K., (2014) Prevalence of Sexual Dysfunction among females in a university community in Enugu, Nigeria. Nigerian Journal of Clinical Practice; 17:791-796.

[16] Ogunbode, O.O., Aimakhu, C.O., Ogunbode, A.M., Adebusoye, L.A., Owonikoko, K.M., (2019). Sexual Dysfunction among women in a Nigerian gynecological outpatients' unit. Tropical Journal of Obstetrics and Gynaecology; 36:61-6.

[17] Wischmann, T., Schilling, K., Toth, B., Rösner, S., Strowitzki, T., Wohlfarth, K., Kentenich, H., (2014) Sexuality, self-esteem and partnership quality in infertile women and men. Geburtshilfe Frauenheilkd. 74(8):759-763.

[18]Zarbakhsh, M., Dinani, P.T., Rahmani, M., (2013). The relationship between sexual self-esteem and all its components with marital satisfaction.in athletic women of Tehran. European Online Journal of Natural and Social Sciences. 2;2:.200-206.

[19] Behboodi-Moghadam, Z., Salsali, M., EftekharArdabily, H., Vaismoradi, M, Ramezanzadeh, F., (2013) Experiences of infertility through the lens of Iranian infertile women: a qualitative study. Jpn $J$ Nurs Sci. 10(1):41-46. 